\title{
Imaging of the hypoxia-inducible factor pathway: insights into oxygen sensing
}

\author{
U. Berchner-Pfannschmidt, S. Frede, C. Wotzlaw and J. Fandrey
}

ABSTRACT: The transcription factor complex hypoxia-inducible factor (HIF)-1 controls the expression of most genes involved in adaptation to hypoxic conditions. HIF-1 is a heterodimer composed of oxygen-labile HIF- $\alpha$ and constitutively expressed HIF- $\beta$ subunits. The oxygendependent regulation of HIF- $\alpha$ is a multistep process that includes degradation under normoxia but stabilisation, translocation into the nucleus and activation under hypoxic conditions.

The present paper summarises the contributions of optical methods to the understanding of oxygen-dependent regulation of the HIF-1 pathway. The tissue- and cell-specific distribution of HIF- $\alpha$ was visualised immunohistochemically and by immunofluorescence. Transcriptional activity of HIF-1 was monitored using green fluorescent protein as a reporter under control of hypoxia response elements in living cells, spheroids and tumour tissues in living mice. With cyan and yellow variants of green fluorescent protein fused to HIF subunits and regulatory proteins, subcellular distribution, migration and interaction were imaged in vivo by means of fluorescence recovery after photo-bleaching and fluorescence resonance energy transfer. Noninvasive imaging of these cellular and molecular processes by laser scanning microscopy complements ex vivo molecular biology assays and provides an additional spatial and temporal dimension to the understanding of the HIF-1 pathway.

KEYWORDS: Fluorescence recovery after photo-bleaching, fluorescence resonance energy transfer, green fluorescent protein fusion proteins, hypoxia-inducible factor-1, immunohistology, in vivo imaging

$\mathrm{n}$ response to reduced oxygenation, mammalian cells activate hypoxia-inducible factor (HIF)-1, which regulates transcription of genes involved in angiogenesis, erythropoiesis, glycolysis, iron metabolism and cell survival [1]. In addition to its role in oxygen homeostasis, in vivo studies have revealed a specific role of HIF-1 during ischaemia, inflammation and various cancers, as well as during development [1].

HIF-1 is a heterodimeric basic helix-loop-helix/ PER/ARNT/SIM (PAS) domain transcription factor, composed of a stable and constitutively expressed $\beta$-subunit (HIF-1 $\beta$, also known as aryl hydrocarbon receptor nuclear translocator $(\mathrm{ARNT})$ ) and an inducible $\alpha$-subunit (HIF-1 $\alpha$ ), the levels of which are controlled by cellular oxygen concentration (fig. 1). In addition to the ubiquitous HIF- $1 \alpha$, the HIF- $\alpha$ family contains two other members, HIF-2 $\alpha$ (also referred to as endothelial PAS domain protein-1) and HIF- $3 \alpha$, both of which have a more restricted tissue expression [2, 3]. Whereas HIF-2 $\alpha$ is directly involved in hypoxic gene regulation, most notably in endothelial cells, HIF- $3 \alpha$ might be a negative regulator of hypoxia-inducible gene expression [4].

HIF- $1 \alpha$ is rapidly degraded under normoxic conditions, when it is hydroxylated at two proline residues within the oxygen-dependent degradation domain by prolyl hydroxylase domain (PHD) proteins 1-3 (fig. 2) [5]. This post-translational modification serves as a recognition motif for subsequent ubiquitination by the E3 ubiquitin ligase activity of the von Hippel-Lindau tumour suppressor protein ( $\mathrm{pVHL}$ ), thus targeting HIF-1 $\alpha$ for degradation by the proteasome. Hypoxic

Previous articles in this series: No. 1: Wagner PD. The biology of oxygen. Eur Respir J 2008; 31: 887-890. No. 2: Zhou G, Dada LA, Sznajder Jl. Regulation of alveolar epithelial function by hypoxia. Eur Respir J 2008; 31: 1107-1113.

\section{AFFILIATIONS}

Institut für Physiologie, Universität Duisburg-Essen, Essen, Germany.

CORRESPONDENCE

J. Fandrey

Institut für Physiologie

Universität Duisburg-Essen

Hufelandstrasse 55

45122 Essen

Germany

Fax: 492017234648

E-mail: joachim.fandrey@uni-due.de

Received:

January 282008

Accepted:

January 312008

SUPPORT STATEMENT

This work received financial support from the Deutsche

Forschungsgemeinschaft (grants FA225/18-2 and FA225/19-2) and from the European Commission under FP6 (contract no. LSHM-CT2005-018725, PULMOTENSION). J.

Fandrey received travel

reimbursement from the European Respiratory Society for attending the Fifth Lung Science Conference in Taormina, Italy.

\section{STATEMENT OF INTEREST}

A statement of interest for J. Fandrey can be found at

www.erj.ersjournals.com/misc/

statements.shtml 


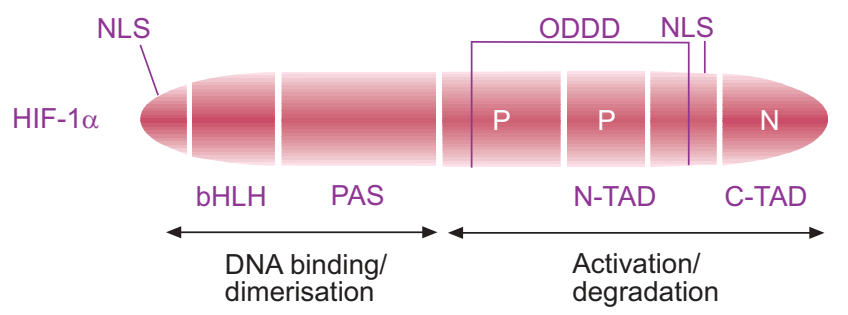

HIF-1 $\beta$

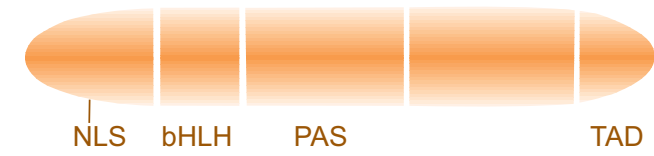

FIGURE 1. Structure of hypoxia-inducible factor (HIF)-1 subunits. The human HIF- $1 \alpha$ subunit (826 amino acids) and the constitutively expressed HIF-1 $\beta$ subunit (789 amino acids) of the HIF-1 complex belong to the group of basic helix-loophelix (bHLH)/PER/ARNT/SIM (PAS) proteins. bHLH/PAS domains mediate DNA binding and heterodimerisation of the subunits. Transactivation of the HIF-1 complex is mediated by the $\mathrm{N}$-terminal transactivation domain (N-TAD) and the Cterminal transactivation domain (C-TAD) containing asparaginyl residue $803(\mathrm{~N})$. Degradation of HIF- $1 \alpha$ under normoxic conditions is dependent on the oxygendependent degradation domain (ODDD). P: proline residues 402 and 564; NLS: nuclear localisation signal.

conditions inhibit prolyl hydroxylation, leading to stabilisation of HIF-1 $\alpha[6,7]$.

Stabilised HIF-1 $\alpha$ translocates into the nucleus, where it heterodimerises with HIF-1 $\beta$ (fig. 2). The HIF-1 complex binds to DNA regulatory sequences called hypoxia response elements (HREs), which are present in the promoter or enhancer regions of HIF-1 target genes [8]. After recruiting transcriptional coactivators, such as CREB (cAMP response element binding)-binding protein (CBP)/p300, the target gene expression is induced [9]. The interaction of HIF-1 $\alpha$ with CBP/p300 is also oxygen controlled via hydroxylation (fig. 2). An asparagylhydroxylase called factor inhibiting HIF-1 modifies the Cterminal transactivation domain (C-TAD) of HIF- $1 \alpha$ and inhibits its association with $\mathrm{CBP} / \mathrm{p} 300$ when oxygen is available [10]. Thus, hypoxia, apart from stabilising HIF-1 $\alpha$, can also lead to activation of transcriptional activity. Furthermore, movement of HIF- $1 \alpha$ between cell compartments appears to be dependent on the oxygen concentration [11]. The present review focuses on the contributions of optical methods to the improvement of the understanding of oxygen-dependent regulation of the HIF-1 pathway. The tissue- and cellspecific distribution of the oxygen-controlled HIF- $\alpha$ subunits was visualised by immunohistochemistry and immunofluorescence. Transcriptional activity of HIF-1 was monitored using green fluorescent protein (GFP) as a reporter under control of HREs in living cells, spheroids and living mice. Using the cyan and yellow variants (CFP and YFP, respectively) of GFP to generate fusion proteins with HIF subunits and regulatory proteins, the subcellular distribution, migration and interaction were imaged in vivo by means of fluorescence recovery after photo-bleaching (FRAP) and fluorescence resonance energy transfer (FRET). Noninvasive imaging of these cellular and molecular processes by two-photon laser microscopy complements ex vivo molecular biology assays and provides an additional spatial and temporal dimension to the understanding of the cellular hypoxic response.

\section{TISSUE- AND CELL-SPECIFIC EXPRESSION OF THE HIF $=\alpha$ SUBUNITS}

In order to better understand the mechanisms and sites of HIF- $\alpha$ regulation, the distribution patterns of HIF- $\alpha$ in normal tissue, and changes that occurred during physiological development, malignant transformation or under ischaemia have been examined by immunohistochemistry.

The spatial and temporal distribution of HIF-1 $\alpha$ in vivo has been determined in healthy mice in response to a reduced inspired oxygen partial pressure. Immunohistochemical examination of brain, kidney, liver, heart and skeletal muscle has revealed that HIF- $1 \alpha$ protein was present in the nucleus, even under normoxic conditions. Nuclear and cytoplasmic staining of HIF- $1 \alpha$ has been found to increase in response to systemic hypoxia ( $6 \%$ oxygen), except in the lung [12]. These findings suggest that physiological oxygen concentrations in normal tissue, ranging $2-5 \%$ oxygen [13], allow levels of HIF-1 $\alpha$ that may help to maintain homeostasis of cellular activities, e.g. by controlling steady-state expression of genes required to provide cellular energy.

In addition to hypoxia, other signals generated during cellular differentiation and in response to growth factors may regulate HIF-1 $\alpha$ expression in normoxic organs within distinct cell types. Strong accumulation of HIF- $1 \alpha$ protein was detected in specific cells, such as in neurons of the hippocampus, the dentate gyrus in the brain and in hepatocytes in the liver [12]. In contrast, HIF$1 \alpha$ was undetectable in mouse pulmonary cells even under hypoxia (6\% oxygen) [12]. However, HIF- $1 \alpha$ expression was induced when ferret lungs were ventilated with $<1 \%$ oxygen for $4 \mathrm{~h}$. Upon re-oxygenation, HIF- $1 \alpha$ was rapidly degraded, with a half-life of $<1 \mathrm{~min}$ [14]. Within the hypoxic ferret lung, HIF-1 $\alpha$ was expressed in most cell types, including smooth muscle, alveolar cells and vascular epithelium [14].

Alternatively, cells that do not contain HIF- $1 \alpha$ may preferentially express HIF- $2 \alpha$ to adapt to hypoxia. Although HIF- $2 \alpha$ was not detectable under normoxic conditions, systemic normobaric hypoxia (8\% oxygen) and anaemic hypoxia $(0.1 \%$ carbon monoxide) induced HIF-2 $\alpha$ in all organs of rats investigated, including brain, heart, lung, kidney, liver, pancreas and intestine [15]. The time course and amplitude of induction varied between organs, apart from the lung, where HIF- $2 \alpha$ protein was only very weakly increased.

Immunohistochemistry revealed nuclear accumulation in distinct cell populations in each tissue, which were always nonparenchymal in some organs (kidney, pancreas and brain), predominantly parenchymal in others (liver and intestine) or equally distributed (myocardium) [15]. In the lung, however, immunohistochemistry on tissue from rats exposed to $8 \%$ oxygen showed strong and frequent nuclear staining of type II pneumocytes, while anaemic hypoxia only weakly increased HIF- $2 \alpha$ abundance. In contrast, the endothelial cells of pulmonary arteries showed strong nuclear signals in response to both forms of hypoxia [15]. Thus, HIF- $2 \alpha$ may play an important role in the transcriptional response to hypoxia in vivo that is complementary, rather than redundant, to HIF- $1 \alpha$. 
a)

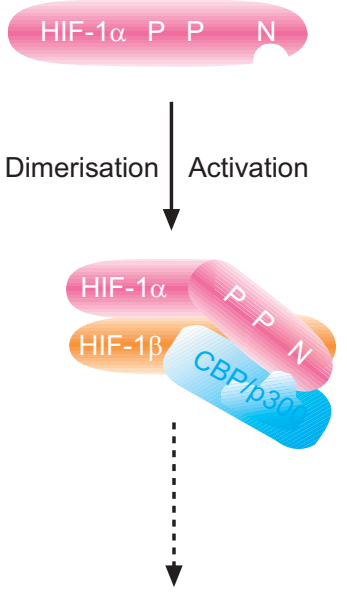

HIF-1-dependent transcription b)

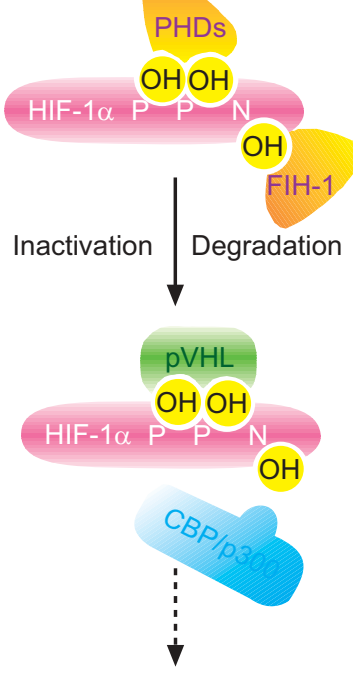

Proteasomal degradation

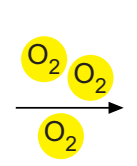

FIGURE 2. Hypoxia-inducible factor (HIF)-1-mediated oxygen sensing of transcription. The schematic illustrates how the $\alpha$-subunit of the heterodimeric transcription factor HIF-1 conveys hypoxic conditions to transcriptional control. a) Under hypoxic conditions, HIF- $1 \alpha$ dimerises with $\mathrm{HIF}-1 \beta$ and binds to HIFresponsive target genes, such as erythropoietin or vascular endothelial growth factor. After recruitment of the transcriptional coactivator CREB (CAMP response element binding)-binding protein (CBP)/p300 to HIF-1 $\alpha$ and additional binding of gene- or tissue-specific transcriptional cofactors, HIF-1-dependent transcription is induced. b) Under normoxic conditions, HIF-1 $\alpha$ is absent because it is inactivated and immediately degraded by the proteasomal machinery. The oxygen sensors translating the oxygen concentration into changes in $\mathrm{HIF}-1 \alpha$ are oxygen-dependent hydroxylases: factor inhibiting HIF-1 (FIH-1) and prolyl hydroxylase domaincontaining proteins $1-3$ (PHDs). In the presence of oxygen, $\mathrm{FlH}-1$ hydroxylates asparaginyl residue $803(\mathrm{~N})$ within the $\mathrm{C}$-terminal transactivation domain of $\mathrm{HIF}-1 \alpha$, preventing the recruitment of $\mathrm{CBP} / \mathrm{p} 300$ to the $\mathrm{HIF}-1$ complex, which leads to reduction of transcriptional activity. PHDs hydroxylate two prolyl (P) residues (P402 and P564) within the oxygen-dependent degradation domain of HIF- $1 \alpha$, allowing binding of the von Hippel-Lindau tumour suppressor protein ( $\mathrm{pVHL}$ ). pVHL functions as a recognition element for the multiprotein E3 ubiquitin ligase complex, which targets HIF- $1 \alpha$, via polyubiquitination, for proteasomal degradation. Whereas dimerisation and transactivation of the HIF-1 complex takes place in the cell nuclei, it is still under discussion whether the oxygen sensing process of $\mathrm{FlH}-1 / \mathrm{PHDs}$, the binding of $\mathrm{PVHL}$ and the proteasomal degradation can take place in both cytoplasm and nucleus. OH: hydroxyl group.

The expression patterns and the extent to which HIF- $1 \alpha$ and $-2 \alpha$ exert similar or distinct functions in vivo have been investigated by comparative immunohistochemistry of different cell types from kidneys and heart in response to hypoxia or ischaemia [16-18]. To study the expression of HIF- $1 \alpha$ versus $-2 \alpha$ in kidneys, rats were exposed to systemic hypoxia, anaemia induced by bleeding, functional anaemia $(0.1 \%$ carbon monoxide), renal ischaemia or cobalt(II) chloride $\left(\mathrm{CoCl}_{2} ;\right.$ known to mimic hypoxia). These treatments led to marked nuclear accumulation of HIF- $1 \alpha$ and $-2 \alpha$ that was selective with respect to cell type, kidney zone and experimental conditions [16]. HIF$1 \alpha$ was mainly induced in tubular cells, whereas HIF- $2 \alpha$ was expressed in endothelial cells of glomeruli and in peritubular endothelial cells and fibroblasts. Despite the well-known heterogeneity of renal oxygen tensions $(<0.1-7 \%$ oxygen), no signals from HIF- $\alpha$ units were observed in the kidneys of normal rats [16]. In contrast, HIF- $\alpha$ proteins were expressed in developing human and rat kidneys during glomerulogenesis and nephrogenesis. HIF- $1 \alpha$ seems to be primarily involved in tubulogenesis and HIF- $2 \alpha$ in renal vasculogenesis; both isoforms are found during glomerulogenesis [18]. Similarly, during first trimester development of the human lung, which takes place in the relatively hypoxic environment of the uterus, HIF$1 \alpha$ was found to be mainly restricted to the branching epithelium, whereas HIF- $2 \alpha$ was also present in the vascular structures of the lung parenchyma [19]. The different spatial expression of HIF- $\alpha$ species may reflect their different roles in pulmonary development. HIF-1 $\alpha$ appears to be more important for organogenesis, whereas the function of HIF- $2 \alpha$ seems to be the fine-tuning of pulmonary vascularisation and remodelling [19]. These data support the notion that HIF- $1 \alpha$ and $-2 \alpha$ already exert distinct functions during early development of organs, as well as their function in response to hypoxic or ischaemic conditions in adult tissues.

In normal human tissue very little expression of HIF- $1 \alpha$ or $-2 \alpha$ has been found. Significant HIF-2 $\alpha$ expression was found to be limited to Kupffer cells in the liver and bone marrow macrophages. This HIF- $2 \alpha$ staining was predominantly cytoplasmic, with a small amount of nuclear localisation in some macrophages [20]. Weak HIF-1 $\alpha$ expression was also found in foetal hepatocytes, proliferating B-cells in tonsils and spleen, and seminiferous tubules of the testis, and was correlated with cell proliferation [21].

In contrast, HIF- $1 \alpha$ and $-2 \alpha$ proteins were detected in most types of human tumours and their metastases, including glial, breast, ovarian, gastric, colon, hepatocellular, pancreatic, prostate, bladder and renal carcinomas [20-23]. Within tumours, the extent, intensity, intracellular localisation and distribution of HIF- $1 \alpha$ and $-2 \alpha$ staining was heterogeneous [20, 21]. HIF- $1 \alpha$ staining was primarily nuclear, but some cytoplasmic staining of HIF- $1 \alpha$ was also detected in colon, breast, pancreas and prostate adenocarcinomas. However, HIF- $1 \alpha$ was not observed in tumour-adjacent stroma tissue [21]. In renal cell carcinoma, staining for HIF- $1 \alpha$ was cytoplasmic and nuclear, whereas HIF-2 $\alpha$ was exclusively nuclear. In a hepatocellular carcinoma, nuclear and cytoplasmic staining for both proteins was observed [20]. In the perinecrotic regions of tumours, the HIF- $1 \alpha$ protein staining tended to be stronger than that of HIF- $\alpha$ [20]. HIF- $1 \alpha$-positive cells were also prominent at tumour margins and surrounding areas of neovascularisation [21]. Variable amounts of nuclear expression of HIF- $1 \alpha$ and $-2 \alpha$, or incompletely overlapping patterns of the two HIF- $\alpha$ subunits, suggest that hypoxia-independent mechanisms in the tumour micro-environment contribute to the upregulation of HIF- $\alpha$ proteins in cancers.

\section{MONITORING TRANSCRIPTIONAL ACTIVITY OF HIF-1}

Although immunohistochemical analysis can be useful in determining whether HIF- $\alpha$ proteins are present at higher levels in cancer cells compared with surrounding normal tissue, it does not reveal whether the HIF-1 complex is transcriptionally active. To investigate the transcriptional activity of HIF-1 in vivo, several HREs are usually fused to GFP or its variants. In response to hypoxia or $\mathrm{CoCl}_{2}$, induced 
HIF-1-dependent GFP expression was observed in several cell lines both by flow cytometry analysis and fluorescence microscopy [24-26].

To monitor and assess the level of endogenous HIF-1 activity during tumour development and growth, SERGANOVA et al. [24] have developed a retroviral vector for stable transduction of tumour cells, bearing a dual reporter gene cassette with an HIF-1-inducible 8HRE-thymidine kinase/GFP fusion and a constitutively expressed reporter gene, Discosoma red fluorescent protein 2/xanthine phosphoribosyltransferase. This dual reporter system allowed imaging of HIF-activity in spheroids or in xenografts in living mice, both by confocal laser microscopy as well as by noninvasive in vivo positron emission tomography (PET) of a radiolabelled probe [27]. In multicellular spheroids grown from transduced C6 rat glioma cells, HIF-1 activity was detectable within the central region when spheroids exceeded $350 \mu \mathrm{m}$ in diameter and had a hypoxic core zone. These findings are in agreement with those for immunostained multicellular prostate tumour spheroids (350-400 $\mu \mathrm{m}$ in diameter) analysed by quantitative laser scanning microscopy, which showed an increase in HIF- $1 \alpha$ expression in the more central parts, correlating with reduced pericellular oxygen levels as measured by microelectrodes [28] In contrast, INDOVINA et al. [26] reported that three-dimensional cell organisation leads to almost immediate HIF-1 activation even in small spheroids $(100 \mu \mathrm{m}$ in diameter) grown from osteosarcoma cells stably transfected with an HRE-enhanced (E)GFP reporter vector, when analysed in vivo with twophoton laser microscopy. Since $100 \mu \mathrm{m}$ is still within the diffusion limit for oxygen, the observed HIF activity in small spheroids was most likely not due to hypoxia alone, but may have been caused by paracrine factors produced during early three-dimensional cell growth [26].

In addition, HIF-1 activity has been shown to be heterogeneous and dependent on tumour size in xenografts transfected with HIF-1-specific GFP reporter vectors. With increased diameter $(>3 \mathrm{~mm})$ of $\mathrm{C} 6$ rat glioma tumours, a marked increase in HIF-1 transcriptional activity was observed in the core regions of tumours, as visualised by micro-PET and confirmed by fluorescence microscopy of excised tumours. Ischaemiareperfusion injury in small tumour xenografts caused a rapid induction of HIF-1 transcriptional activity that persisted for longer $(24 \mathrm{~h})$ than in normal tissues, revealing that, besides hypoxia, oncogenic signalling may play a role in controlling HIF-1 activity [24]. In order to monitor HIF-1 activity in real time in tumour xenografts, LIU et al. [25] chose a 5HRE promoter fused to destabilised EGFP with a half-life reduced to $<2$ h (d2EGFP). HIF-1 activity, monitored by EGFP fluorescence intensity, correlated with hypoxic treatment, and reoxygenation resulted in a rapid decrease in HIF-1 activity. Within solid tumours of living mice, HIF-1 activity was heterogeneous, and immunohistochemical analysis confirmed that d2EGFP-expressing regions reflecting HIF-1 activity were almost identical to areas staining for the hypoxia marker pimonidazole [25]. On closer inspection, however, d2EGFPpositive cells appeared to be more abundant than pimonidazole-stained cells. This might either reflect a lower threshold for HIF-1 activation compared with the formation of pimonidazole adducts or be due to nonhypoxic activation of HIF-1 that does not increase pimonidazole staining [25].

\section{SUBCELLULAR DISTRIBUTION OF HIF SUBUNITS AND INTERACTION WITH REGULATORY FACTORS}

It has been widely shown via immunofluorescence that HIF-1 $\alpha$ accumulates in nuclei of many cell lines in response to hypoxia, hypoxia-mimicking agents, inflammatory cytokines, nitric oxide and hormones [29-34]. The nuclear accumulation of HIF- $1 \alpha$ is a consequence of either reduced degradation or enhanced synthesis of HIF-1 $\alpha$. Using GFP fusion protein constructs and deletion variants, KALLIO et al. [11] identified a nuclear localisation signal motif in the C-terminus of HIF-1 $\alpha$ that mediated the translocation into the nucleus. Nuclear translocation itself seems to be constitutive, independent of oxygen availability or pVHL status in cells infected with an adenovirus expressing GFP fused to the HIF- $1 \alpha$ subunit [35]. During re-oxygenation, HIF- $1 \alpha$ is relocated to the cytoplasm in order to be degraded by the proteasome in many cell lines [11, $35,36]$. Export of HIF-1 $\alpha$ upon re-oxygenation is not mediated by chromosome maintenance region (CRM) 1 /Exportin1, since the nuclear export was unaffected by the drug leptomycin B [35] and a typical nuclear export signal has not been identified within HIF-1 $\alpha$. However, GROULX and LEE [35] provided evidence that $\mathrm{pVHL}$ plays a dual role, being involved in both degradation of HIF- $1 \alpha$ and export to the cytoplasm. GROULX and LEE [35] showed that interaction of HIF-1 $\alpha$ and pVHL occurs in the nucleus, where HIF- $1 \alpha$ is ubiquitinated before it is exported through a non-CRM1-dependent mechanism to the cytoplasm. According to this model, HIF- $1 \alpha$ becomes completely located in the nucleus under hypoxia, because it does not interact with pVHL and, therefore, cannot be exported to the cytoplasm [35].

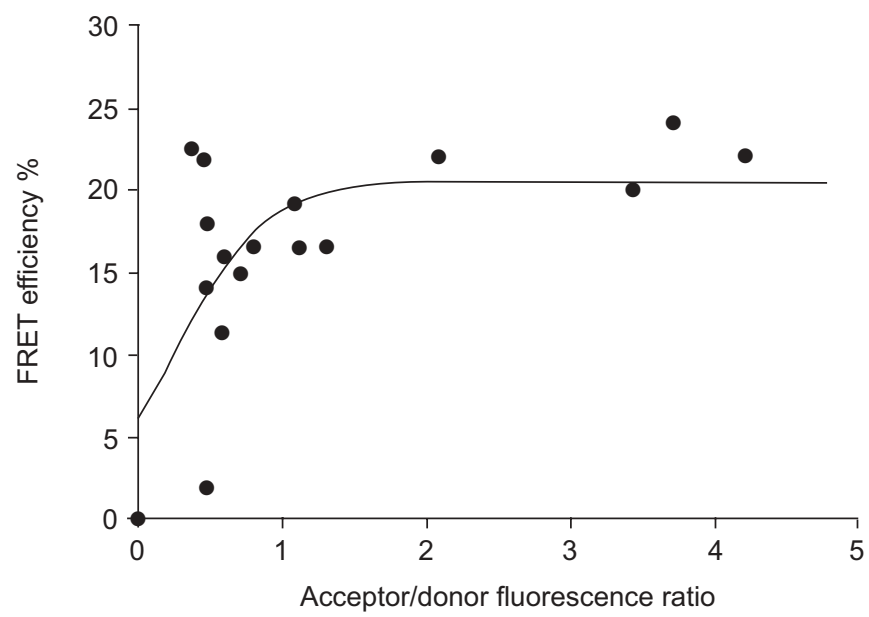

FIGURE 3. In vivo analysis of hypoxia-inducible factor (HIF)-1 $\alpha$ and HIF-1 dimerisation using fluorescence resonance energy transfer (FRET). Enhanced cyan fluorescent protein (ECFP)-HIF-1 $\alpha$ and enhanced yellow fluorescent protein (EYFP)HIF-1 $\beta$ were coexpressed in U2OS osteosarcoma cell nuclei and imaged by twophoton laser scanning microscopy, while the cells were kept under hypoxia According to the theory of FRET, energy from the donor molecule (ECFP-HIF-1 $\alpha$ ) is transferred to the acceptor (EYFP-HIF-1 $\beta$ ) if the two molecules come closer than $10 \mathrm{~nm}$. FRET efficiencies from cell nuclei were calculated using the acceptor bleaching method. The mean FRET efficiency of ECFP-HIF-1 $\alpha$ and EYFP-HIF-1 $\beta$ interaction depends on their relative expression within the respective cell nucleus. Therefore, the distance between the molecules was determined $(6.2 \mathrm{~nm})$ when a plateau was reached [48] 


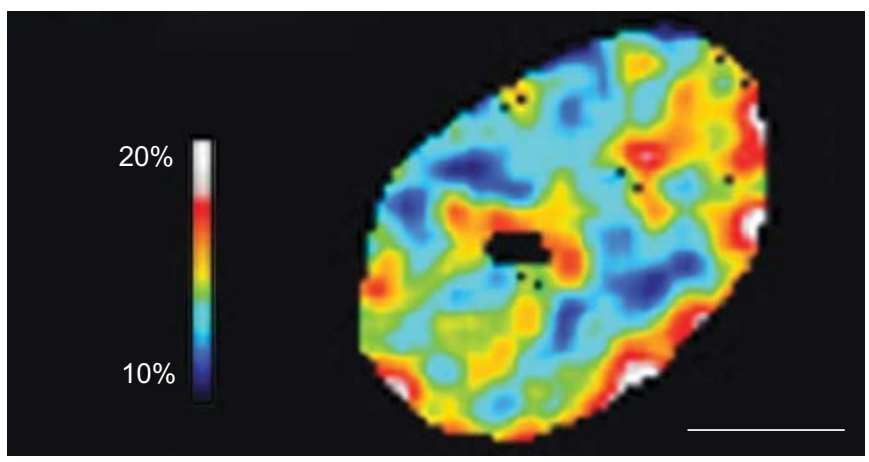

FIGURE 4. Subnuclear distribution of hypoxia-inducible factor (HIF)-1 $\alpha$ and HIF-1 $\beta$ dimerisation, analysed by fluorescence resonance energy transfer (FRET). U2OS osteosarcoma cells were transfected with enhanced cyan fluorescent protein (ECFP)-HIF-1 $\alpha$ and enhanced yellow fluorescent protein (EYFP)-HIF-1 $\beta$. Under hypoxia, both fusion proteins were expressed in cell nuclei and FRET was imaged by laser scanning microscopy. The distribution of FRET efficiencies within a single cell nucleus was estimated using the sensitised FRET method [50] and visualised in false colour mode, as indicated by the colour bar. Subnuclear variations in FRET efficiency most likely reflect local variation in the mean distance between the ECFPand EYFP-labelled HIF-1 subunits. Scale bar $=2 \mu \mathrm{m}$.

However, it has been previously reported that trapping of HIF- $1 \alpha$ either in the nucleus or in the cytoplasm does not prevent HIF-1 $\alpha$ degradation [37], implying that HIF-1 $\alpha$ degradation can occur in both compartments. Indeed, proteasome complexes and pVHL are present in both the cytoplasm and nucleus [38-40]. Furthermore, localisation studies have shown that the oxygen sensors initiating HIF- $1 \alpha$ degradation, namely the PHD proteins, are also found in both compartments [41-43]. Consistent with these findings, ZHENG et al. [44] recently showed that compartmentalisation of HIF- $1 \alpha$ degradation and subcellular distribution are regulated in a cell type-specific manner. Fragments of the N-terminal transactivation domain (N-TAD) of HIF-1 $\alpha$ that were able to inhibit pVHL-mediated degradation when fused with GFP were targeted to different cell compartments, allowing identification of two possible cell types [44]. In highly proliferating or transformed cells (e.g. HepG2 hepatoma cells), HIF-1 $\alpha$ degradation occurs mainly in the cytoplasm. Under hypoxia, HIF- $1 \alpha$ translocates to the nucleus and, upon re-oxygenation, the protein needs to be relocated to the cytoplasm to be efficiently degraded. In this cell type, retention of HIF- $1 \alpha$ in the nucleus can protect it from degradation. In contrast, in primary endothelial cells (e.g. from mouse brain), HIF- $1 \alpha$ can be degraded with equal efficiency in the nucleus and cytoplasm. In this cell type, HIF- $1 \alpha$ is present in both compartments under conditions of normoxia, hypoxia or reoxygenation. Furthermore, MYLONIS et al. [45] suggested that the activity level of the mitogen-activated protein kinase (MAPK) pathway contributes to the cell type-specific subcellular distribution of HIF- $1 \alpha$. Amino acid residues were identified within the inhibitory domain of HIF-1 $\alpha$ that, when phosphorylated, enhanced nuclear accumulation of GFP-HIF$1 \alpha$. Since MAPK pathway activity is highly connected to the proliferation state of the cell, the distribution of HIF- $1 \alpha$ could be differentially regulated in highly transformed, rapidly proliferating cells and primary, slow-growing cells.
In contrast to HIF- $1 \alpha$, the $\beta$-subunit of the HIF- 1 complex is found exclusively in the nuclear compartment and is unaffected by oxygen concentration. Furthermore, HIF- $1 \alpha$ accumulation and nuclear translocation occur independently of HIF$1 \beta$, as shown by immunofluorescence in HIF- $1 \beta$-mutant mouse hepatoma cells and embryonic stem cells [36]. However, HIF$1 \beta$ has been shown to be indispensable for HIF-1 DNA binding and transactivation [46].

Within the hypoxic nucleus, endogenous HIF- $1 \alpha$ and HIF-1 $\beta$ are colocalised in speckle-like structures, as observed by immunofluorescence combined with three-dimensional visualisation studies [47]. These speckle-like structures were also observed when ECFP-HIF- $1 \alpha$ and EYFP-HIF- $1 \beta$ fusion proteins were coexpressed, but not when each construct was transfected alone, implying that these structures are the sites of HIF-1 complexes [48]. Using FRAP, it has been observed that EYFP-HIF-1 $\beta$ moves faster than ECFP-HIF- $1 \alpha$ ( $50 \%$ recovery of fluorescence after $31 \mathrm{~s}$ compared with $65 \mathrm{~s}$, respectively) when cells were cotransfected with both fusion proteins [48]. This indicates that the subunits can move separately and, therefore, do not always form HIF-1 complexes inside the nucleus. To analyse the interaction of HIF- $1 \alpha$ and HIF-1 $\beta$ in the DNAbound HIF-1 complex in living cells, ECFP or EYFP was fused to the N-terminus or C-terminus of the full-length HIF-1 subunits and subjected to FRET analysis. The highest FRET efficiency and, thus, closest association of the fusion proteins was observed when ECFP and EYFP were located at the $\mathrm{N}$ terminus of the HIF- $1 \alpha$ and HIF- $1 \beta$ subunits, respectively (fig. 3). The fluorophore-labelled N-termini of the HIF-1 subunits were colocalised as close as $6.2 \mathrm{~nm}$ and the C-termini as close as $6.7 \mathrm{~nm}$, and even the N- and C-termini of the HIF-1 complex were not further apart than $7.4 \mathrm{~nm}$ [48], indicating that the HIF-1 complex is more compact than previously thought. Furthermore, the subnuclear distribution of HIF- $1 \alpha / \beta$ heterodimerisation was heterogeneous when imaged by sensitised FRET (fig. 4). Different FRET efficiencies within the cell nucleus may result from local variation in the mean distance between the ECFP- and EYFP-labelled HIF-1 subunits. Since experimental $\mathrm{X}$-ray crystallography data on the threedimensional structure of the HIF-1 complex are not yet available, due to the low solubility of the subunits [49], FRET experiments are the method of choice to gain more insights into the three-dimensional organisation of the HIF-1 complex and its nuclear distribution in living cells under different oxygen concentrations.

In addition, HIF-1-mediated transcription requires the recruitment of coactivators, such as $\mathrm{CBP} / \mathrm{p} 300$ and factors belonging to the steroid receptor coactivator (SRC)/p160 family, to build a transcriptionally active HIF-1/coactivator complex [9]. RUAS et al. [51] showed that colocalisation of CFP-mouse-HIF- $1 \alpha$ and YFP-CBP in nuclear accumulation foci was dependent on the integrity of the C- and N-TADs of HIF- $1 \alpha$, which correlated with HIF-1-mediated activation of transcription. Further colocalisation studies of CFP or YFP fusion proteins of HIF$1 \alpha$, HIF- $1 \beta$, CBP and SRC-1 suggest that CBP, besides interacting with HIF- $1 \alpha$, can also interact with HIF-1 $\beta$, thereby stabilising the formation of the HIF- $1 \alpha / \beta$ heterodimer [52]. In addition, CBP was found to mediate the interaction between SRC-1 and HIF-1 $\alpha$, indicating that CBP is the mediator of HIF-1/coactivator formation [9]. 
To activate transcription in response to hypoxia in a tissuespecific manner, further cofactors have to be recruited to HIF-1 or the HIF-1/coactivator complex, e.g. hepatocyte nuclear factor- 4 to activate transcription of erythropoietin in the liver [53]. The challenge for the near future will be to analyse the dynamics and architecture of the assembly of the HIF-1/ coactivator/cofactor multiprotein complexes in vivo, by combining FRAP and FRET methods.

\section{CONCLUSIONS}

Immunohistology and immunofluorescence revealed that the oxygen-labile $\alpha$-subunits of HIF- 1 and -2 are hardly detectable in normal tissues of human adults, although the oxygen concentration within the tissue ranges $3-5 \%$. However, accumulation of HIF- $\alpha$ is observed during early development of organs, in response to ischaemia and in tumour tissue. HIF- $1 \alpha$ and $-2 \alpha$ staining is heterogeneous and only partially overlapping, suggesting that the $\alpha$-subunits are not redundant and play different roles. By expressing GFP under control of an HRE in tumour cells, multicellular spheroids or xenographs of living mice, HIF-1 transcriptional activity has been shown to be increased in response to hypoxia or ischaemia. Under hypoxic conditions, HIF- $1 \alpha$ is shown to be localised in the nucleus of most cells, although in other cells HIF- $1 \alpha$ is also found in the cytoplasm. By expressing different GFP fusion proteins of HIF$1 \alpha$ in living cells, the subcellular localisation was found to be cell specific and regulated by the degradation pathway of HIF-1 $\alpha$.

Within the nucleus, HIF- $1 \alpha$ and HIF-1 $\beta$ were localised in speckle-like structures, where interaction of the subunits takes place. Heterodimerisation of ECFP-HIF- $1 \alpha$ und EYFP-HIF-1 $\beta$ was analysed in living cells using FRAP and FRET methods. Distances between HIF- $1 \alpha$ and $-1 \beta$ fusion proteins were calculated as 6.2-7.4 nm. Furthermore, HIF-1-mediated transcription requires the recruitment of several transcriptional coactivators and tissue-specific cofactors to the HIF-1 complex.

The challenge for the near future will be to analyse the dynamics and architecture of the assembly of the multiprotein complexes involved in the transduction of the hypoxic signal in living cells, by combining fluorescence recovery after photobleaching and fluorescence resonance energy transfer with noninvasive methods such as two-photon laser microscopy.

\section{REFERENCES}

1 Semenza GL. Hypoxia-inducible factor 1: oxygen homeostasis and disease pathophysiology. Trends Mol Med 2001; 7: 345-350.

2 Ema M, Taya S, Yokotani N, Sogawa K, Matsuda Y, FujiiKuriyama Y. A novel bHLH-PAS factor with close sequence similarity to hypoxia-inducible factor $1 \alpha$ regulates the VEGF expression and is potentially involved in lung and vascular development. Proc Natl Acad Sci USA 1997; 94: 4273-4278.

3 O'Rourke JF, Tian YM, Ratcliffe PJ, Pugh CW. Oxygenregulated and transactivating domains in endothelial PAS protein 1: comparison with hypoxia-inducible factor- $1 \alpha$. J Biol Chem 1999; 274: 2060-2071.

4 Makino Y, Cao R, Svensson K, et al. Inhibitory PAS domain protein is a negative regulator of hypoxia-inducible gene expression. Nature 2001; 414: 550-554.
5 Fandrey J, Gorr TA, Gassmann M. Regulating cellular oxygen sensing by hydroxylation. Cardiovasc Res 2006; 71: 642-651.

6 Schofield CJ, Ratcliffe PJ. Signalling hypoxia by HIF hydroxylases. Biochem Biophys Res Commun 2005; 338: 617-626.

7 Berra E, Ginouvès A, Pouysségur J. The hypoxia-induciblefactor hydroxylases bring fresh air into hypoxia signalling. EMBO Rep 2006; 7: 41-45.

8 Wenger RH, Stiehl DP, Camenisch G. Integration of oxygen signaling at the consensus HRE. Sci STKE 2005; 2005: re12.

9 Ruas JL, Poellinger L. Hypoxia-dependent activation of HIF into a transcriptional regulator. Semin Cell Dev Biol 2005; 16: 514-522.

10 Lando D, Peet DJ, Whelan DA, Gorman JJ, Whitelaw ML. Asparagine hydroxylation of the HIF transactivation domain a hypoxic switch. Science 2002; 295: 858-861.

11 Kallio PJ, Okamoto K, O’Brien S, et al. Signal transduction in hypoxic cells: inducible nuclear translocation and recruitment of the $\mathrm{CBP} / \mathrm{p} 300$ coactivator by the hypoxiainducible factor-1 $\alpha$. EMBO J 1998; 17: 6573-6586.

12 Stroka DM, Burkhardt T, Desbaillets I, et al. HIF-1 is expressed in normoxic tissue and displays an organspecific regulation under systemic hypoxia. FASEB J 2001; 15: 2445-2453.

13 Acker H, Berchner-Pfannschmidt U, Wotzlaw C, Huckstorf C, Streller T. Optical analysis of the oxygensensing signal pathway. In: Lahiri S, Semenza GL, Prabhakar NR, eds. Oxygen Sensing: Responses and Adaptation to Hypoxia (Lung Biology in Health and Disease). New York, Marcel Dekker, Inc., 2003; pp. 519-533.

14 Yu AY, Frid MG, Shimoda LA, Wiener CM, Stenmark K, Semenza GL. Temporal, spatial, and oxygen-regulated expression of hypoxia-inducible factor-1 in the lung. Am J Physiol 1998; 275: L818-L826.

15 Wiesener MS, Jürgensen JS, Rosenberger C, et al. Widespread hypoxia-inducible expression of HIF- $2 \alpha$ in distinct cell populations of different organs. FASEB J 2003; 17: 271-273.

16 Rosenberger C, Mandriota S, Jürgensen JS, et al. Expression of hypoxia-inducible factor- $1 \alpha$ and $-2 \alpha$ in hypoxic and ischemic rat kidneys. J Am Soc Nephrol 2002; 13: 1721-1732.

17 Jürgensen JS, Rosenberger C, Wiesener MS, et al. Persistent induction of HIF- $1 \alpha$ and $-2 \alpha$ in cardiomyocytes and stromal cells of ischemic myocardium. FASEB J 2004; 18: 1415-1417.

18 Bernhardt WM, Câmpean V, Kany S, et al. Preconditional activation of hypoxia-inducible factors ameliorates ischemic acute renal failure. J Am Soc Nephrol 2006; 17: 1970-1978.

19 Groenman FA, Rutter M, Wang J, Caniggia I, Tibboel D, Post M. Effect of chemical stabilizers of hypoxia-inducible factors on early lung development. Am J Physiol Lung Cell Mol Physiol 2007; 293: L557-L567.

20 Talks KL, Turley H, Gatter KC, et al. The expression and distribution of the hypoxia-inducible factors HIF- $1 \alpha$ and HIF- $2 \alpha$ in normal human tissues, cancers, and tumorassociated macrophages. Am J Pathol 2000; 157: 411-421. 
21 Zhong H, De Marzo AM, Laughner E, et al. Overexpression of hypoxia-inducible factor $1 \alpha$ in common human cancers and their metastases. Cancer Res 1999; 59: 5830-5835.

22 Zagzag D, Zhong H, Scalzitti JM, Laughner E, Simons JW, Semenza GL. Expression of hypoxia-inducible factor $1 \alpha$ in brain tumors: association with angiogenesis, invasion, and progression. Cancer 2000; 88: 2606-2618.

23 Bos R, Zhong H, Hanrahan CF, et al. Levels of hypoxiainducible factor- $1 \alpha$ during breast carcinogenesis. J Natl Cancer Inst 2001; 93: 309-314.

24 Serganova I, Doubrovin M, Vider J, et al. Molecular imaging of temporal dynamics and spatial heterogeneity of hypoxia-inducible factor- 1 signal transduction activity in tumors in living mice. Cancer Res 2004; 64: 6101-6108.

25 Liu J, Qu R, Ogura M, Shibata T, Harada H, Hiraoka M. Real-time imaging of hypoxia-inducible factor-1 activity in tumor xenografts. J Radiat Res (Tokyo) 2005; 46: 93-102.

26 Indovina P, Collini M, Chirico G, Santini MT. Threedimensional cell organization leads to almost immediate HRE activity as demonstrated by molecular imaging of MG-63 spheroids using two-photon excitation microscopy. FEBS Lett 2007; 581: 719-726.

27 Blasberg R. Imaging gene expression and endogenous molecular processes: molecular imaging. J Cereb Blood Flow Metab 2002; 22: 1157-1164.

28 Wartenberg M, Ling FC, Müschen M, et al. Regulation of the multidrug resistance transporter P-glycoprotein in multicellular tumor spheroids by hypoxia-inducible factor (HIF-1) and reactive oxygen species. FASEB J 2003; 17: 503-505.

29 Görlach A, Diebold I, Schini-Kerth VB, et al. Thrombin activates the hypoxia-inducible factor-1 signaling pathway in vascular smooth muscle cells: role of the p22(phox)containing NADPH oxidase. Circ Res 2001; 89: 47-54.

30 Stolze I, Berchner-Pfannschmidt U, Freitag P, et al. Hypoxiainducible erythropoietin gene expression in human neuroblastoma cells. Blood 2002; 100: 2623-2628.

31 Liu Q, Berchner-Pfannschmidt U, Möller U, et al. A Fenton reaction at the endoplasmic reticulum is involved in the redox control of hypoxia-inducible gene expression. Proc Natl Acad Sci USA 2004; 101: 4302-4307.

32 Frede S, Freitag P, Otto T, Heilmaier C, Fandrey J. The proinflammatory cytokine interleukin $1 \beta$ and hypoxia cooperatively induce the expression of adrenomedullin in ovarian carcinoma cells through hypoxia inducible factor 1 activation. Cancer Res 2005; 65: 4690-4697.

33 Berchner-Pfannschmidt U, Petrat F, Doege $\mathrm{K}$, et al. Chelation of cellular calcium modulates hypoxia-inducible gene expression through activation of hypoxia-inducible factor-1 $\alpha$. J Biol Chem 2004; 279: 44976-44986.

34 Berchner-Pfannschmidt U, Yamac H, Trinidad B, Fandrey J. Nitric oxide modulates oxygen sensing by hypoxiainducible factor 1-dependent induction of prolyl hydroxylase 2. J Biol Chem 2007; 282: 1788-1796.

35 Groulx I, Lee S. Oxygen-dependent ubiquitination and degradation of hypoxia-inducible factor requires nuclearcytoplasmic trafficking of the von Hippel-Lindau tumor suppressor protein. Mol Cell Biol 2002; 22: 5319-5336.

36 Chilov D, Camenisch G, Kvietikova I, Ziegler U, Gassmann M, Wenger RH. Induction and nuclear translocation of hypoxia-inducible factor-1 (HIF-1): heterodimer- ization with ARNT is not necessary for nuclear accumulation of HIF-1 $\alpha$. J Cell Sci 1999; 112: 1203-1212.

37 Berra E, Roux D, Richard DE, Pouysségur J. Hypoxiainducible factor- $1 \alpha$ (HIF- $1 \alpha$ ) escapes $\mathrm{O}_{2}$-driven proteasomal degradation irrespective of its subcellular localization: nucleus or cytoplasm. EMBO Rep 2001; 2: 615-620.

38 Lee S, Chen DY, Humphrey JS, Gnarra JR, Linehan WM, Klausner RD. Nuclear/cytoplasmic localization of the von Hippel-Lindau tumor suppressor gene product is determined by cell density. Proc Natl Acad Sci USA 1996; 93: 1770-1775.

39 Wójcik C, DeMartino GN. Intracellular localization of proteasomes. Int J Biochem Cell Biol 2003; 35: 579-589.

40 Karhausen J, Kong T, Narravula S, Colgan SP. Induction of the von Hippel-Lindau tumor suppressor gene by late hypoxia limits HIF-1 expression. J Cell Biochem 2005; 95: 1264-1275.

41 Metzen E, Berchner-Pfannschmidt U, Stengel $\mathrm{P}$, et al. Intracellular localisation of human HIF-1 $\alpha$ hydroxylases: implications for oxygen sensing. J Cell Sci 2003; 116: 1319-1326.

42 Soilleux EJ, Turley H, Tian YM, Pugh CW, Gatter KC, Harris AL. Use of novel monoclonal antibodies to determine the expression and distribution of the hypoxia regulatory factors PHD-1, PHD-2, PHD-3 and FIH in normal and neoplastic human tissues. Histopathology 2005; 47: 602-610.

43 Jokilehto T, Rantanen K, Luukkaa M, et al. Overexpression and nuclear translocation of hypoxia-inducible factor prolyl hydroxylase PHD2 in head and neck squamous cell carcinoma is associated with tumor aggressiveness. Clin Cancer Res 2006; 12: 1080-1087.

44 Zheng X, Ruas JL, Cao R, et al. Cell-type-specific regulation of degradation of hypoxia-inducible factor $1 \alpha$ : role of subcellular compartmentalization. Mol Cell Biol 2006; 26: 4628-4641.

45 Mylonis I, Chachami G, Samiotaki M, et al. Identification of MAPK phosphorylation sites and their role in the localization and activity of hypoxia-inducible factor- $1 \alpha$. J Biol Chem 2006; 281: 33095-33106.

46 Salceda S, Beck I, Caro J. Absolute requirement of aryl hydrocarbon receptor nuclear translocator protein for gene activation by hypoxia. Arch Biochem Biophys 1996; 334: 389-394.

47 Berchner-Pfannschmidt U, Wotzlaw C, Merten E, Acker H, Fandrey J. Visualization of the three-dimensional organization of hypoxia-inducible factor- $1 \alpha$ and interacting cofactors in subnuclear structures. Biol Chem 2004; 385: 231-237.

48 Wotzlaw C, Otto T, Berchner-Pfannschmidt U, Metzen E, Acker H, Fandrey J. Optical analysis of the HIF-1 complex in living cells by FRET and FRAP. FASEB J 2007; 21: 700-707.

49 Erbel PJ, Card PB, Karakuzu O, Bruick RK, Gardner KH. Structural basis for PAS domain heterodimerization in the basic helix-loop-helix-PAS transcription factor hypoxiainducible factor. Proc Natl Acad Sci USA 2003; 100: 1550415509.

50 Feige JN, Sage D, Wahli W, Desvergne B, Gelman L. PixFRET, an ImageJ plug-in for FRET calculation that can 
accommodate variations in spectral bleed-throughs. Microsc Res Tech 2005; 68: 51-58.

51 Ruas JL, Poellinger L, Pereira T. Functional analysis of hypoxia-inducible factor- $1 \alpha$-mediated transactivation. Identification of amino acid residues critical for transcriptional activation and/or interaction with CREB-binding protein. J Biol Chem 2002; 277: 38723-38730.
52 Ruas JL, Poellinger L, Pereira T. Role of CBP in regulating HIF-1-mediated activation of transcription. J Cell Sci 2005; 118: 301-311.

53 Stockmann C, Fandrey J. Hypoxia-induced erythropoietin production: a paradigm for oxygen-regulated gene expression. Clin Exp Pharmacol Physiol 2006; 33: 968-979. 